\title{
Los frisos antropomorfos en la cerámica funeraria de La Aguada de la Colección Muñiz Barreto
}

BÁRBARA BALESTA ${ }^{1}$ Y NORA ZAGORODNY ${ }^{2}$

\section{RESUMEN}

Se analizan los frisos antropomorfos presentes en vasijas funerarias del cementerio de La Aguada Orilla Norte (Catamarca, Argentina). La muestra forma parte de la Colección Muñiz Barreto depositada en el Museo de La Plata. Asimismo, se realiza un estudio contextual de las tumbas en que se hallan dichas vasijas. Como resultado del análisis se propone un ajuste de la clasificación vigente de los personajes antropomorfos, basada en los atributos reconocidos en cada representación.

Palabras claves: frisos antropomorfos - cerámica funeraria - tipología.

\section{ABSTRACT}

Anthropomorphic figures incised on funerary vessels belonging to La Aguada Orilla Norte burial ground (Catamarca, Argentina) are analyzed. These vessels, that form part of the Muñiz Barreto Collection (Museo de La Plata), are analyzed contextually with the tombs in which they were found. As a result we propose an adjustment to the current classification of the anthropomorphic figures, based on the recognizable attributes of each representation.

Key words: anthropomorphic figures - funerary vessels typology.

Recibido: febrero 2002. Manuscrito revisado aceptado: septiembre 2003.

\section{Introducción}

El objetivo del trabajo consiste en la identificación, descripción y análisis de los frisos con decoración antropomorfa presentes en vasijas pertenecientes a los acompañamientos funerarios de tumbas del cementerio de La Aguada Orilla Norte del arroyo de La Aguada. Este cementerio se localiza en el Departamento de Belén (Provincia de Catamarca, Argentina).

1 Facultad de Ciencias Naturales y Museo. Paseo del Bosque s/nº (1900) La Plata, Argentina. Email: bbalesta@netverk.com.ar

2 Facultad de Ciencias Naturales y Museo. Paseo del Bosque s/nº (1900) La Plata, Argentina. Email: norazago@way.com.ar
Los materiales analizados forman parte de la Colección Benjamín Muñiz Barreto depositada en el Museo de La Plata. Las piezas fueron recuperadas por el Ingeniero Federico Wolters en la décima y undécima expediciones al Noroeste Argentino durante la década del ' 20.

El cementerio está constituido por 200 tumbas con un total de 1.479 objetos de diferente índole: cerámica, piedra, hueso, metal, malaquita y pigmentos. La cerámica es el ítem más representativo, correspondiendo a 1.292 piezas.

Se ha realizado un análisis contextual de las tumbas en donde han sido encontradas estas piezas, que comprende: modalidad de entierro (múltiple o individual); asignación etaria de los restos; características de los objetos asociados (otras piezas de cerámica, hueso, piedra, metal, malaquita y pigmentos) y su trascendencia desde el punto de vista cuantitativo. El cruce de esta información apunta a recuperar la significación de su presencia en este tipo de contexto.

Asimismo, se han analizado las figuras antropomorfas y se han comparado con la tipología establecida por González (1977) y González y Baldini (1991 y 1992). Como resultado de este análisis se propone un ajuste de dicha clasificación.

\section{La Colección Muñiz Barreto}

La colección debe su nombre al estanciero homónimo, quien radicado en la provincia de Buenos Aires, dedicó su vida y fortuna a comprar y recuperar tesoros arqueológicos. La mayor parte de la Colección -aproximadamente 10.900 piezas- proviene de tareas sistemáticas de excavación subvencionadas por él.

Esta vasta colección es el resultado de las labores de investigación de campo, de excavación de tumbas y relevamiento topográfico de sitios de ocupación indígena, realizados entre los años 1919 y 1929 en el Noroeste Argentino (provincias de Jujuy, 
Tucumán, Salta, La Rioja y Catamarca). Estos trabajos fueron iniciados en 1919 por don Carlos Schuel a quien se le unió en 1920, en Jujuy, Wladimiro Weisser, quien posteriormente lo reemplazó en forma definitiva. Este era un alemán nacionalizado argentino que fue dirigido en su tarea por el prestigioso científico Salvador Debenedetti, quien también estuvo a cargo de la clasificación y catalogación de los materiales y en varias ocasiones se trasladó al campo para supervisar las tareas de excavación. A las órdenes de Weisser trabajó un equipo de profesionales ocupados en distintas funciones como la restauración de piezas, dibujo, fotografía y catalogación, entre los cuales se destaca Federico Wolters. A la muerte de Weisser, en 1926, la dirección de los trabajos recayó en Wolters.

La exhaustividad con que los trabajos fueron registrados queda atestiguada por el hecho de que si bien los intereses de Barreto se referían a piezas funerarias completas y finas, los materiales fueron recogidos en su totalidad, salvo que se deshicieran como en el caso de muchas urnas. No obstante, en estos casos, la existencia y características de las piezas eran fielmente registradas.

En 1931 la colección fue depositada en el Museo de La Plata, momento en que Muñiz Barreto la ofreció en venta a dicha institución, efectivizándose la misma el 2 de septiembre de 1933, días después de la muerte de su propietario.

\section{Las excavaciones en La Aguada}

Los cementerios de la localidad de La Aguada fueron excavados durante la décima y undécima expediciones, que abarcaron desde principios de 1928 hasta junio de 1929.

Wolters no escribe diarios de viaje, pero en su correspondencia hay un registro minucioso de las tareas realizadas para recuperar los materiales. Esta información se complementa con planos, dibujos de corte y planta de las tumbas y descripciones del contexto del hallazgo detalladas en sus libretas de campo. Además, existen fotografías del paisaje, labores de campo y dibujos de los materiales hallados.

Con fecha 18 de febrero de 1928, Wolters envía a Barreto, bajo el título "Explicaciones de exploraciones y excavaciones en el vallecito "La Aguada', Depto. Belén. Prov. Catamarca”, un informe en donde da una ubicación y descripción bastante detalladas del valle y de sus pobladores. Al respecto comenta que es “...un vallecito de más o menos $1 \mathrm{~km}$ de largo y la misma distancia de ancho" (X Expedición: 36).

Identifica las señales de restos arqueológicos:

“...un estudio exacto del vallecito mostraría todavía en muchas partes algunas piedras plantadas como restos de viviendas o señas de sepulcros, más algunas tejas finas, esas señas dan la conclusión de una región antigua." (X Expedición: 39-40).

Describe las excavaciones y las características de los sepulcros señalando que:

"Las excavaciones por un corte frontal hasta $6 \mathrm{~m}$ de profundidad en la banda Norte sobre el río 'La Aguada' en una tierra firme y casi sin cambio resultan buenos éxitos.

Los sepulcros en construcción cencillo una vez sin pircas, otra vez con una fila o muralla de piedras de un lado del sepulcro como puerta al mismo y con algunas piedras o lajas como tapa del sepulcro, igual del tipo de sepulcros de 'La Ciénega', pero la tierra menos salitrosa y los esqueletos mejor conservado.

Algunas vecez encontramos sobre el sepulcro in diferentes alturas otros yacimientos en forma suelto o como urna funeraria con párvulos y objetos pequeños” (X Expedición: 40).

A continuación realiza una descripción de los hallazgos, destacando la figura del “...dragón pintado en negro y colorado obscuro sobre fondo amarillo de teja enlozada..." (X Expedición: 41). Respecto de otros materiales refiere "Los objetos de piedra presentan obras artísticas..., también los objetos de metal (cobre) y hueso..." (X Expedición: 41).

A modo de conclusión expresa que "Las observaciones dan la conclusión de la misma tribu que de La Ciénega, pero por las enormes profundidades y objetos mejores una época más vieja" (X Expedición: 41/42).

\section{Descripción general del cementerio}

Como ya se ha comentado, el cementerio La Aguada Orilla Norte está constituido por 200 tumbas. 
La mayoría de los individuos se encuentran inhumados en forma directa. No obstante, 14 tumbas corresponden a entierros en urnas.

En función de las características de los ajuares se puede afirmar que no todos los enterratorios son contemporáneos o corresponden a Aguada. Se han reconocido, dentro del cementerio, tumbas que por sus piezas han sido adscritas como Saujil, Belén, y lisas indeterminadas (Sempé 1995).

Según la cantidad de cuerpos depositados en cada unidad de entierro podemos distinguir entre tumbas individuales y múltiples. Sobre un total de 200 tumbas, 151 corresponden a la modalidad de entierro individual $(75.5 \%)$ y 49 son múltiples $(24.5 \%)$. Estas últimas incluyen un máximo de seis individuos por unidad de entierro.

En la estimación de la edad probable de los individuos inhumados, Wolters diferenció las categorías niños/párvulos, jóvenes y adultos. No obstante, a los efectos de este estudio y teniendo en cuenta que no contamos con la posibilidad de contrastar la información del soporte documental con los restos esqueletarios, ya que los mismos fueron dejados in situ por los expedicionarios, creemos que resulta más ajustado efectuar una diferenciación de nuestro universo, unificando las categorías en términos de adultos y subadultos (Ubelaker 1978).

Sabemos que los responsables de las expediciones se basaron en las características dentarias para la determinación de la edad. Al respecto comenta Weisser que "....según los dientes se podía calcular la edad ...” (VII Expedición: 106).

Consecuentemente, con respecto a la edad relativa de los cuerpos allí enterrados, se registran 126 tumbas correspondientes a adultos, 65 a subadultos y nueve mixtas. Si se cruza la información respecto de la modalidad de entierro con la edad, se obtiene que, dentro de las tumbas múltiples, 35 corresponden a adultos, cinco a subadultos y nueve son mixtas.

En nuestro universo no contamos con especificaciones acerca de la distinción sexual entre los individuos exhumados. De acuerdo a la información disponible para la época, resultaba complicado realizar dicho diagnóstico. Al respecto, LehmannNitsche señala específicamente que se ha “....abs- tenido de tasar el sexo de los cráneos, tarea de éxito más que dudoso en cráneos americanos..." (1910 Ms: 22).

Otro ítem analizado fue la presencia o ausencia de estructuras de piedra asociadas a las tumbas como parte de su concepción constructiva. Las mismas se presentan en la mayoría de los casos como pequeñas paredes que pueden delimitar totalmente o en algún sector, a los cuerpos enterrados. Dentro del total de tumbas se relevaron 130 (65\%), que presentan estructuras de piedra que delimitan el enterratorio.

A fin de evaluar la significación diferencial de los acompañamientos funerarios se tomaron como indicadores: a) presencia de material cerámico, y b) presencia de material no cerámico. En el análisis del primer ítem se consideró la cantidad de objetos acompañantes, en tanto en el segundo se tomaron en cuenta los diferentes tipos de materia prima usada para confeccionar los objetos.

A los efectos de realizar un análisis del material cerámico desde el punto de vista cuantitativo se han agrupado los entierros en:

- aquéllos que no presentan acompañamiento cerámico (siete tumbas que representan el $3.5 \%)$,

- los que exhiben entre uno y tres objetos (88 tumbas que constituyen el 44\%: 31 con un objeto, 29 con dos y 28 con tres),

- los que tienen entre cuatro y 14 piezas (90 tumbas que implican el 45\%: 44 con cuatro a seis y 46 con siete a 14), y

- los que presentan entre 15 y 28 objetos (15 tumbas que representan el $7.5 \%$ ).

Esta división obedece al hecho de que, en primer lugar, se aplicó el criterio de distinción entre presencia/ausencia del material, que permitió separar las unidades de entierro, que no presentaban acompañamiento funerario, del resto. En los otros casos se puede ver que existen altas frecuencias para las tumbas con una a tres piezas, similares a las registradas para las unidades con cuatro a 14 objetos. Este último grupo se puede dividir en dos subgrupos: las unidades que exhiben entre cuatro y seis piezas $(n=44)$ y las que presentan entre siete y $14(n=46)$. Por otra parte, es escaso el número de tumbas con 15 a 28 objetos. 
De acuerdo a lo observado en términos cuantitativos se puede señalar que:

- la mayoría de las tumbas presentan acompañamiento cerámico $(96.5 \%)$;

- se registra un mínimo de una pieza cerámica por tumba y un máximo de 28 ;

- los ajuares que constan de 15 o más objetos son altamente significativos desde este punto de vista.

Si cruzamos la información resultante del análisis cuantitativo con la modalidad de entierro se puede observar que hay una tendencia que marca la existencia de una relación entre la cantidad de objetos cerámicos por tumba y dicha modalidad. Las tumbas que presentan mayor cantidad de piezas suelen corresponder a entierros múltiples. Esta tendencia se manifiesta con más claridad a partir de la presencia de siete o más objetos. Aquéllas unidades de entierro que contienen entre 19 y 28 piezas pertenecen exclusivamente a entierros múltiples.

Como ya se ha establecido, los acompañamientos funerarios estuvieron compuestos en su gran mayoría por objetos cerámicos. Sin embargo, se registra la aparición en algunas tumbas, de objetos realizados en otras materias primas: piedra, cobre, malaquita, hueso y muestras minerales que fueron identificadas por los expedicionarios como pigmentos. $^{3}$

La existencia de éstos es indicativa de significación particular ya que su presencia es exigua (13\% de la composición de los acompañamientos), en líneas generales en los casos de piedra a través de bolas, morteros y manos, vasos y pipas; la malaquita en collares y pulseras; el cobre en collares, pulseras e instrumentos y el hueso en formas tubulares que fueron categorizadas por los expedicionarios como tubos, flautas o simplemente objetos sin indicación funcional.

Las materias primas utilizadas para confeccionar bolas, morteros, vasos y pipas fueron identificadas a través de lupa de mano. La mayor parte de las mismas corresponde a rocas ígneas y metamórficas. Todos los materiales identificados para la confección de esta clase de objetos corresponden a recursos locales.

Estas muestras están en proceso de análisis.
Cabe recordar que la presencia de cobre y malaquita se detecta en forma conjunta. Los yacimientos de cobre más próximos se encuentran en las Sierras Pampeanas de Famatina (La Rioja) y Capillitas (Catamarca) (Angelelli 1950 y 1983; Angelelli et al. 1970). Sin embargo, existe una referencia acerca de la existencia de minerales de cobre en el Distrito Culampajá (Departamento de Belén), cercano al área abarcada en este estudio. No obstante, se trataría de pequeñas manifestaciones que se hallan dentro de un yacimiento aurífero.

La escasez de objetos confeccionados con estos materiales podría implicar dificultades para su obtención, ya sea desde el punto de vista de la localización como de la cantidad de mineral extraíble.

Los cálculos finales dan cuenta de que:

- en 58 tumbas hay material lítico $(29 \%)$

- en 21 tumbas hay objetos de metal (10.5\%)

- en 9 tumbas hay malaquita (4.5\%)

- en 18 tumbas hay presencia de hueso (9\%)

- en 13 tumbas hay trozos de pigmentos minerales en forma de panes $(6.5 \%)$.

\section{Confección de la muestra y descripción de las piezas}

La muestra se ha conformado con piezas cerámicas que exhiben frisos con representaciones de figuras antropomorfas de cuerpo completo. Se trata de vasijas grises decoradas mediante la técnica de grabado. Se tomaron en cuenta también aquellas que presentan cuerpo antropomorfo y cabeza felínica, en las que parece que la figura humana estuviera usando una máscara. Este tipo particular de representaciones se registra en 27 tumbas, con un total de 31 vasijas.

En este trabajo no hemos considerado el análisis de aquellas representaciones que exhiben sólo algunos atributos antropomorfos (p.e., cabezas) combinados con figuras de diferente índole.

La morfología de las piezas corresponde a los tipos cuenco y cuenco grande en la clasificación de Balfet y colaboradores (1992).

El tratamiento de las figuras se caracteriza por presentarlas mayoritariamente de frente. En tér- 
minos generales, los atributos principales que las componen son los siguientes:

- las cabezas son generalmente subcirculares,

- los tocados son muy diversos e incluyen figuras felinizadas de distinto tipo. El felino se puede presentar: de perfil y cuerpo entero; dos felinos de perfil compartiendo el cuerpo con sus caras mirando a ambos lados; de perfil enfrentados; con o sin patas delanteras. Por último se detectaron representaciones de partes de cuerpos felínicos: manchas, patas y sectores dentados que podrían asimilarse a fauces. Sólo en dos casos los felinos aparecen en su totalidad y en forma independiente de la figura humana.

- En la mayoría de los casos se presentan orejeras circulares de carácter simple,

- los ojos en general son circulares u ovales. Las pupilas, cuando están representadas son círculos, óvalos o líneas.

- Algunas de las figuras muestran pintura facial,

- las bocas, cuando se representan, pueden ser: líneas horizontales, círculos concéntricos, óvalos y rectángulos. En algunos casos presentan líneas internas a modo de dientes. En el caso de las figuras que exhiben cabeza felínica, muestran fauces correspondientes a estos animales.

- Los cuerpos están totalmente cubiertos por líneas rectas en zigzag, círculos irradiados combinados con líneas rectas, líneas rectas paralelas y círculos concéntricos interpretados como manchas felínicas.

- algunas de las figuras presentan pectorales de forma circular, o subrectangular,

- sólo tres de las figuras analizadas tienen indicación sexual masculina,

- las piernas siempre se ubican con los pies orientados hacia fuera,

- los brazos pueden adoptar distintas posiciones: flexionados hacia arriba, flexionados hacia abajo, extendidos hacia afuera, o combinando dichas posiciones,

- los dedos de pies y manos, cuando se observan, están representados con líneas. Un caso particular es el de la pieza 11784 (Figura 1), que tiene manos circulares y dedos hechos con líneas o triángulos.

\section{Antecedentes para el análisis}

Para el análisis del material se tomó como punto de partida la descripción establecida por González

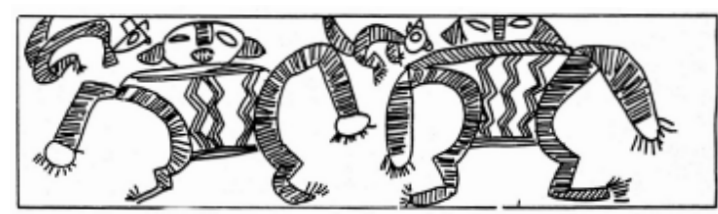

Figura 1. Pieza 11784: muestra manos circulares y dedos hechos con líneas.

(1977) y por González y Baldini (1991 y 1992). Ellos caracterizan a las figuras humanas de $\mathrm{La}$ Aguada, representadas sobre distintos soportes, a través de la presencia de atributos específicos. Como resultado de esta clasificación establecen una jerarquía de dichas imágenes. De acuerdo a González y Baldini:

"El personaje solar más destacado es el 'personaje de las manos vacías' representado en el disco de Lafone Quevedo (González y Baldini 1991), le siguen en importancia el 'personaje del sacrificador' a veces con máscaras felínicas, y el 'personaje de los dos cetros"' (1992:14).

El "Personaje de las Manos Vacías" exhibe como principales atributos dos felinos y dos ofidios fantásticos. González y Baldini (1991) interpretan que el Personaje de las Manos Vacías es una representación directa de la deidad solar.

Una variante de esta imagen es la del "Sacrificador", en la que: “...el personaje central lleva en las manos un hacha o una cabeza cercenada pendiente del codo o de las manos, o ambos a la vez" (González y Baldini 1991: 49). El Sacrificador sería un "guerrero" y además el oficiante en el acto sacrificatorio en honor a la deidad solar "...en el que adquiere casi los propios rasgos del dios" (González y Baldini 1991). Este personaje se distingue, según su forma de representación, en: Sacrificador completo e incompleto. El primero porta armas y cabezas cercenadas, el segundo sólo uno de estos elementos.

Sumado a los anteriores aparece otra imagen denominada el "Enmascarado" que representa a

“...un individuo provisto de una gran máscara felínica, que frecuentemente y por oposición a todas las demás figuras humanas, se la representa de perfil" (González 1977: 181).

También describe al "Personaje de los Dos Cetros", como: 
“...la figura del guerrero visto de frente a cuyos lados, sostenidas por ambas manos, aparecen sus armas constituidas por dardos o estólicas y en algunos casos hachas" (González 1977: 181).

Otro tipo definido por González se denomina "Personaje flanqueado por felinos", del cual no proporciona ejemplos gráficos y a los que describe como "...felinos que se asocian a otros atributos del personaje” (González y Baldini 1991: 36).

Esta terminología pretende facilitar el reconocimiento del rol del personaje representado bajo distintos soportes tecnológicos (cerámica, piedra, textil, madera, hueso), pudiendo de esta manera establecer comparaciones, conexiones espaciales, nexos de continuidad histórica y/o manifestaciones materiales que expresen unidad ideológica.

En tal sentido, se buscó identificar las imágenes de la muestra a partir de la tipología referida. En algunos casos se observó que la clasificación reflejaba claramente los atributos representados, sin embargo, en otros existieron dificultades para la adscripción. Las dificultades obedecen a que en ocasiones resulta difícil identificar de qué tipo de armas se trata, en algunos casos se exhiben figuras sin una descripción exhaustiva y en otros se describen atributos sin ejemplificación gráfica.

Tal el caso de la pieza 11725 (González y Baldini 1991: 41, figuras 7d y 10a) en la que se muestra el mismo tratamiento de la figura humana, sin embargo, el que caracteriza como Personaje de los Dos Cetros (González y Baldini 1991: 41, figura 10a) porta tiraderas en ambas manos y el llamado Sacrificador Incompleto (González y Baldini 1991: 41, figura 7d) porta un hacha en una mano y una tiradera en la otra. Si nos remitimos a las definiciones ofrecidas en los trabajos citados, ambos personajes se confunden.

El tipo denominado "Personaje con máscara felínica" está presente en nuestra muestra a través de dos piezas (Figuras 2 y 3 ).

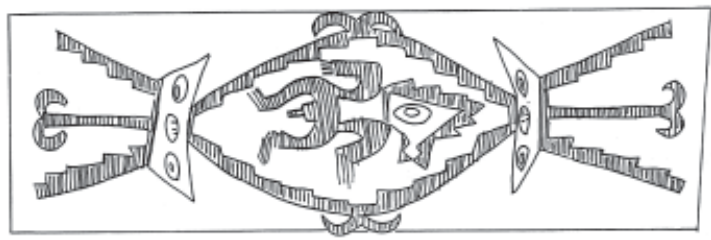

Figura 2. Personaje con máscara felínica.

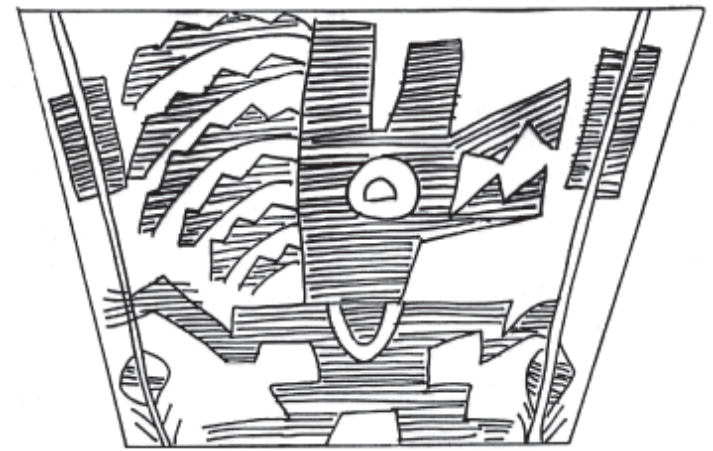

Figura 3. Personaje con máscara felínica.

Creemos que aquéllos a los que describe como "personajes flanqueados por felinos" corresponden a 12 de las piezas relevadas que representan figuras antropomorfas flanqueadas por felinos de perfil.

\section{Fundamentos teóricos para un ajuste de la tipología}

La aproximación temática fue desarrollada por Donnan (1976) en su estudio sobre las claves del sistema simbólico Moche, a partir de un modelo lingüístico. Según este autor, identificando las reglas de expresión utilizadas por un grupo, se pueden deducir patrones artísticos. También afirma que es posible identificar individuos sobre la base de la combinación persistente de características o atributos asociados con ellos, tales como su forma física, indumentaria y objetos que los acompañan. Asimismo, el significado asociado a una figura se puede determinar a través del rango de actividades que desempeña y al entorno en el cual está representada.

El sustento de esta posición se basa en la identificación de grupos recurrentes de figuras y sus posibles variantes, a los que denomina "temas". Donnan no establece un criterio firme acerca de qué es lo que constituye un tema; en el caso de Moche, cualquier imagen o grupo de figuras que se repite en varias vasijas constituye un tema y no todos éstos alcanzan el mismo nivel de interpretación.

Quilter (1997) retoma la postura de Donnan y amplía sus alcances a lo que denomina la aproximación narrativa, postulando la utilidad de este tipo de manifestaciones artísticas para la transmisión de ideas religiosas. Según este autor, existe 
un conjunto de temas que se constituyen en más importantes o significativos o que pueden ser más fácilmente comprendidos por los espectadores. En tal sentido, establece un patrón al que denomina "clave de redundancia escénica" que consiste en que los elementos más importantes de una narrativa son aquéllos que se representan con mayor frecuencia que los menos significativos.

En el caso que nos ocupa nos basamos en las posturas comentadas para identificar a los personajes representados en las vasijas antropomorfas. La "aproximación temática" permite definir "temas" en las representaciones antropomorfas de $\mathrm{La}$ Aguada y las repeticiones de los temas podrían configurar núcleos narrativos de difusión ideológica. No olvidemos que, a diferencia de la cultura occidental, en los grupos americanos prehispánicos la religión, la ideología, los mitos y los rituales estaban intrínsecamente ligados tanto entre sí como a las actividades cotidianas.

\section{Aspectos metodológicos}

Si bien en términos generales la clasificación propuesta por González (1977) y González y Baldini (1991 y 1992) permitió reconocer en la muestra a la mayoría de los personajes tipificados, surgieron dificultades en la identificación de algunos de ellos, lo cual motivó la necesidad de realizar un ajuste en la misma, que permita reflejar la diversidad de las representaciones antropomorfas en el cementerio de La Aguada Orilla Norte. Es por ello que se reformulan y refinan las categorías teniendo en cuenta las características y recurrencias de los personajes registrados en dicho cementerio.

La clasificación propuesta, a diferencia de la anterior, no sigue un criterio jerárquico de los personajes, sino que se basa en los atributos presentes en cada representación. Para denominar a los personajes se utilizó una notación de tipo descriptivo. La misma está fundamentada en la detección de combinaciones de atributos recurrentes en las imágenes, ya sea de los propios personajes, como de los seres y/u objetos acompañantes. A diferencia de las propuestas de González (1977) y González y Baldini (1991, 1992), no se definen roles, sino modalidades de representación, asociaciones de imágenes y persistencia de combinaciones. Posteriormente, se intenta una interpretación de los diferentes casos, a partir del cruce con información proveniente de otras fuentes.
Sobre la base de las observaciones se seleccionaron los criterios diferenciadores que permitieron establecer categorías dentro de las cuales se pudieran incluir las imágenes. Estas fueron básicamente dos: los elementos acompañantes de las figuras antropomorfas y el tratamiento de las cabezas de los personajes. Dentro de los elementos acompañantes se distinguieron armas y felinos. En el tratamiento de las cabezas se diferenciaron la presencia de máscaras y los adornos cefálicos singulares.

A partir de la formulación de la primera categoría se identificaron los siguientes personajes:

1) Personaje con Armas: se decidió utilizar una denominación genérica para este tipo de imágenes, ya que si se tratara de adjudicar roles a través de este tipo de objetos se podría decir que la lanza y la tiradera se identifican con la caza y/o con la guerra, mientras que el hacha se podría vincular más a los sacrificios; por ello consideramos difícil establecer si realmente se trata de un sacrificador quien solamente porta armas.

En cuanto al Personaje de los Dos Cetros, consideramos que su aplicación a nuestros casos resulta problemática, ya que el significado de cetro alude a un bastón de mando que se configura en una insignia de poder, por lo tanto un arma no estaría definiendo en forma inequívoca esta condición. Por ello se define como Personajes con Armas a aquéllos que están acompañados por distintas clases de armas, sujetas o no a sus manos, tales como tiraderas, hachas, dardos, estólicas u otras de difícil identificación. Las figuras se hallan de frente, pudiendo variar la posición de los brazos, mientras que los pies siempre se encuentran hacia ambos lados. Cada individuo dentro de este grupo puede presentar variantes en los siguientes atributos: tocados y/o peinados, pintura facial, orejeras, pectorales, vestimentas. Este grupo constituye uno de los más representados, ya que consta de 11 piezas (Figuras 4 y 5). Esta categoría comprende al Sacrificador y al Personaje de los Dos Cetros definidos por los autores comentados.

2) Personaje con Felinos: se encuentran siempre de frente. Puede haber variantes en las posiciones de los brazos, mientras que los pies siempre se hallan hacia ambos lados. Al igual que en el caso anterior pueden presentar variantes en vestimenta y atributos ornamentales. Esta categoría se co- 


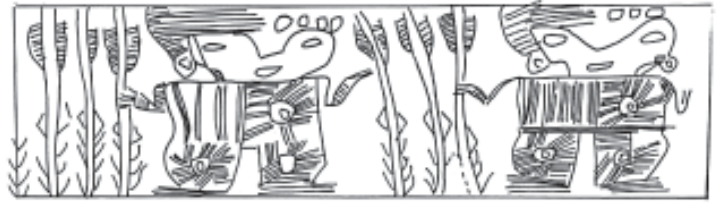

Figura 4. Personajes con armas.

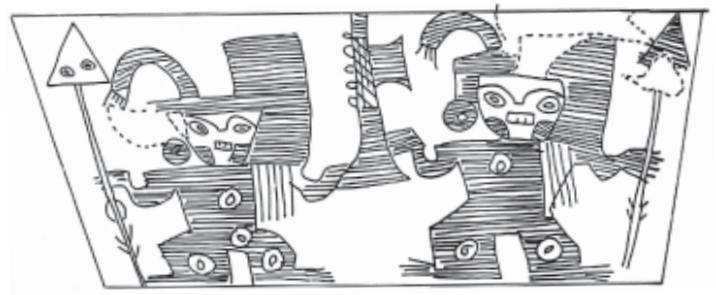

Figura 5. Personajes con armas.

rrespondería con el Personaje Flanqueado por Felinos. Dentro de este grupo proponemos diferenciar dos modos de representación:

a) aquellos que llevan uno o dos felinos sobre los hombros o detrás de la cabeza y se asocian a armas (Figuras 1 y 6);

b) los que se encuentran flanqueados por felinos. Cabe señalar que en este grupo los personajes no se asocian a armas (Figura 7).

3) Personaje Enmascarado: la característica común a este tipo de personaje es el porte de máscaras. Se pueden reconocer dos modalidades:

a) Personaje con Máscara Felínica, manteniendo el nombre propuesto por González. Presentan el cuerpo de frente y la cabeza de perfil, con o sin indicación sexual y se pueden asociar o no con armas (Figuras 2 y 3). Estos personajes presentan la particularidad de sincretizar atributos antropomorfos (cuerpo) y zoomorfos (cabeza) y esto los distingue claramente del resto de las imágenes antropomorfas.

b) Personaje con Máscara No Felínica: representado por la pieza 12304, que exhibe un personaje de frente con indicación sexual y que lleva una máscara no identificada (Figura 8).

4) Personajes con Adornos Cefálicos Singulares y Manos Vacías: todos los personajes presentan adornos cefálicos, generalmente con atributos felínicos y se han categorizado dentro de los denominados Personajes con Felinos.

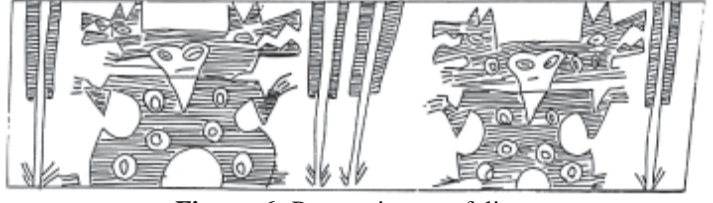

Figura 6. Personajes con felinos.

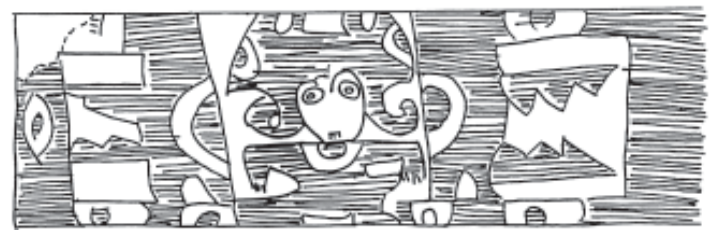

Figura 7. Personaje con felinos.

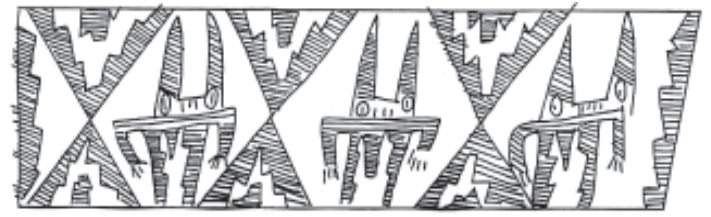

Figura 8. Personaje con máscaras no identificadas.

Los estudios sobre indumentaria y adornos cefálicos indican que:

"La diversidad de los tocados andinos sugiere un mundo de distinciones, ofreciendo a los arqueólogos una vía privilegiada para investigar problemas de identidad étnica, diferencia de estatus y roles, estrategias simbólicas para insertarse en redes de intercambio económico o problemas relacionados con el control político" (Berenguer 1993: 7).

Dentro de la muestra estudiada existen unos pocos ejemplares que se pueden caracterizar como singulares, ya que se apartan de las características felinizadas del resto de los tocados. Por otra parte, se puede señalar que estos personajes no portan objetos en sus manos y el tratamiento de la figura humana es diferente, con una configuración más geometrizada que en el resto. Entre ellos se distinguen dos grupos:

a) Personajes de Cabezas Romboidales y Gorros Cónicos: estos personajes se encuentran enmarcados dentro de figuras geométricas (Figura 9).

b) Personajes con Adornos Cefálicos en Forma de Ancla: la forma del adorno cefálico fue denominada de tal modo por González y Baldini (1992), y es relacionada con representaciones comunes tanto en Moche como Recuay (Figura 10). 


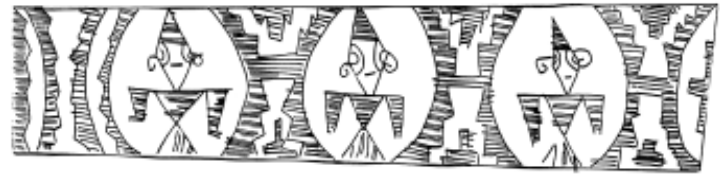

Figura 9. Personajes de cabezas romboidales y gorros cónicos.

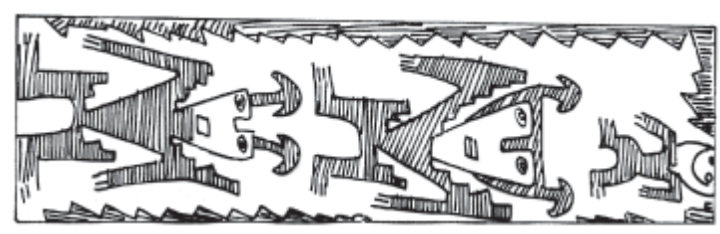

Figura 10. Personajes con adornos cefálicos en forma de ancla.

\section{Análisis contextual de la muestra}

A los fines del análisis contextual se describen a continuación las características de las unidades de entierro en donde se encuentran estas piezas. Como ya comentáramos, la muestra forma parte de un conjunto de 27 tumbas de las cuales 18 son de carácter individual y nueve son múltiples. Se puede observar un crecimiento de la modalidad de entierros múltiples en un $8.5 \%$.

En términos etarios se determinó que cinco tumbas corresponden a la categoría de subadultos (19\%), 19 son de adultos (70\%) y tres son mixtas (corresponden a adultos y subadultos y representan el 11\%). Lo más significativo en este ítem es el aumento en la composición de adultos y tumbas mixtas con el consecuente descenso de tumbas de subadultos.

Dentro de nuestra muestra, combinando los atributos cantidad de individuos por tumba y edad aproximada de los difuntos, podemos observar que todas las tumbas de subadultos son individuales, mientras que las que corresponden a adultos pueden ser individuales o múltiples.

Sobre el total de la muestra, 24 tumbas presentan estructuras en piedra (92\%). En este caso es notable la diferencia respecto del universo, en el cual el $65 \%$ de las tumbas presentan esta característica constructiva.

En función de las categorías establecidas previamente se procedió a contabilizar la cantidad de piezas cerámicas por tumba, obteniéndose un valor mínimo de dos y un máximo de 27 piezas cerámicas en una sola unidad de entierro. Se re- gistraron tres tumbas con una a tres piezas (11\%); 19 con cuatro a 14 vasijas $(70 \%)$ y cinco tumbas con 15 a 27 piezas (19\%). De este análisis se desprende que el $89 \%$ de las tumbas exhiben de cuatro a más objetos.

La cerámica no es la única clase de objetos en el acompañamiento funerario o ajuar. También se pueden encontrar objetos de piedra (en nueve tumbas que representan el $34.6 \%$ de la muestra), de cobre (en dos tumbas que constituyen el $7.7 \%$ ), de hueso (en tres que conforman el $11.5 \%$ ) y panes de pigmentos rojos (en dos tumbas que representan el 7.7\%). Cabe señalar que en la muestra no se registra presencia de objetos de malaquita.

Si bien la comparación del universo con la muestra no arroja diferencias porcentuales cuantitativamente significativas, estos objetos, en función de su escasa presencia en el universo, adquieren una relevancia particular.

No obstante, se pueden destacar algunos datos de interés, como por ejemplo un aumento de un 5.6\% en los objetos de piedra, la ausencia de objetos de malaquita y que casi la totalidad de las tumbas exhiben detalles constructivos en piedra.

\section{Discusión y conclusiones}

A partir del cruce de las observaciones con información aportada por trabajos de otros autores en el tema, se ha conjeturado que en las vasijas con frisos antropomorfos se estarían mostrando representaciones de personajes que reflejan secuencia y/o movimiento, roles específicos, prácticas shamánicas, estados alterados de conciencia, hasta individuos pertenecientes a diferentes etnias, según se comenta a continuación.

La secuencia y/o movimiento se manifiesta en las figuras que a pesar de parecer regidas por el principio de equilibrio simétrico exhiben diferencias en cada lado del cuerpo con respecto al eje bilateral. Por otra parte, en la repetición de las mismas dentro de un friso se manifiestan distinciones que evidencian posturas y/o actitudes corporales a través de las posiciones de los brazos y piernas y/o de los seres acompañantes (Balesta 1995).

Los roles podrían ser identificados a través de la presencia de ciertos atributos ornamentales, como por ejemplo los pectorales. Para etapas previas a 
Aguada, González y Baldini (1992) describen pectorales de forma semilunar con proyección hacia abajo, fabricados sobre láminas de oro o cobre, lisos o decorados, que luego son incorporados por esta entidad en su parafernalia:

"El arquetipo original, mucho más elaborado y posiblemente más temprano, sería una pieza Recuay, al parecer con reminiscencias Chavín, que representa un sacerdote con máscara felínica y este tipo de pectoral sobre sus vestiduras. Esto indicaría una vez más que estamos ante elementos ceremoniales y por lo tanto excepcionales" (p. 10).

En referencia a las prácticas de sacrificios que se hallan testimoniadas por la presencia de individuos despedazados y cabezas cercenadas en centros ceremoniales planificados, González y Baldini (1992) comentan:

"Es indudable que parte de este ceremonial era ejecutado y dirigido por grupos de shamanes-sacerdotes con un entrenamiento previo que pudieron ser, además, los jefes de la comunidad. El estatus de estos sujetos se manifiesta en los suntuosos tocados y peinados, en los hábitos mortuorios y en las insignias que portan; hacha, tiraderas, cetros de mando, aves, discos o adornos en forma de hacha sobre el pecho, perneras, orejeras y escudos que a veces representan la piel del jaguar" (p. 13).

En el mismo trabajo manifiestan dudas respecto de la posibilidad de que estos sujetos portadores de armas estén representando guerreros y apoyan su argumento en “...que las poblaciones Aguada no construyeron sitios fortificados ni se asentaron en lugares estratégicos" (González y Baldini 1992). Sin embargo, creemos que a pesar de que el patrón de asentamiento no esté proporcionando indicaciones de construcciones y/o asentamientos defensivos, no debería descartarse la posibilidad de un conflicto, por lo menos latente, entre las poblaciones de la época, manifestado a través de la iconografía. La instauración de un nuevo orden basado en creencias religiosas pudo haber generado situaciones de tensión intergrupales.

Los estados alterados de conciencia podrían evidenciarse a través del modo de representación de los ojos, en muchos de los casos como círculos concéntricos, forma de expresión que se ha relacionado con el uso de alucinógenos. En tal senti- do, Gordillo (1990) refiere el análisis de una secuencia en un friso de una vasija en la cual el personaje sufre transformaciones en las que evidencia un cambio externo a través de pupilas concéntricas que atribuye al consumo de este tipo de sustancias.

Con respecto a la manifestación de la presencia de otras etnías, podemos referir la existencia de figuras que exhiben elementos diagnósticos, tal el caso de los gorros cónicos y adornos cefálicos en forma de ancla ya comentados.

En tal sentido, Pérez Gollán (1986) comenta que, en varios discos y placas de bronce procedentes del Noroeste Argentino y Bolivia, el personaje central "lleva en la cabeza una especie de gorro cónico que, según los cronistas, era característico del Altiplano boliviano" (Ponce Sanginés 1969, en Pérez Gollán 1986).

En épocas del contacto hispano-indígena P. Pizarro en 1571 describe que:

"Los de una parte de la laguna [del Titicaca] traen unos bonetones en las caueças, de altor de más de un palmo, tan anchos de arriua como de auaxo; los de la otra parte traen los bonetones de arriua angostos y los de auaxo anchos..." (en Berenguer 1993).

En referencia a la relación existente entre la iconografía y el registro arqueológico, para la zona de Ambato, Pérez Gollán y Heredia (1987) comentan que:

“' 'La práctica del cráneo trofeo' o de la 'caza de cabezas' está profusamente representada en los dibujos de los vasos de cerámica. Esta circunstancia puede ser corroborada por los hallazgos realizados durante nuestras investigaciones de restos óseos humanos desarticulados, pero necesitamos todavía la confirmación que se trata de sacrificios o actos de canibalismo realizados, tanto en los sitios ceremoniales, como en las unidades residenciales" (p. 175).

Para el Valle de Hualfín no contamos con evidencias directas ni indirectas de estas prácticas, a saber:

a) en los cementerios no se encuentran cuerpos que puedan indicar descuartizamientos o sacrifi- 
cios; sólo se registra un caso de una tumba $\left(\mathrm{n}^{\mathrm{o}}\right.$ 168) que presenta dos cuerpos más un cráneo;

b) en términos de sacrificios se puede reportar el caso del párvulo hallado en Barrealito de Azampay, pero el mismo podría estar asociado a épocas más tempranas, ya que si como postula Sempé (Sempé et al. 1995) se trata de una ofrenda de fundación, estaría vinculado a la primera época de ocupación del recinto que fue adscrita a Ciénaga.

c) en las representaciones de los frisos no aparece el personaje del sacrificador que posee en una de sus manos una cabeza trofeo;

d) si bien existen representaciones de cabezas aisladas en otro tipo de guardas creemos que la evidencia disponible hasta el momento no resulta suficiente para caracterizarlas como de tipo "trofeo".

Tanto en el caso de Ambato como de Hualfín se puede afirmar que el análisis de la iconografía nos está proporcionando una coincidencia con las características observadas en el registro arqueológico, si bien cabe aclarar que, en Hualfín, aún se espera profundizar en la excavación de sitios de habitación que proporcionen información para contrastar con los datos iconográficos.

Respecto de la alfarería del Ambato, Pérez Gollán y Heredia (1987) plantean la hipótesis de que:

"...hubo una gran uniformidad en el tratamiento de la arcilla y en el proceso de la manufactura, al punto de lograr una homogeneidad que probablemente sólo pudo ser resultado del trabajo de un grupo de especialistas" (p. 171).

Esta afirmación se vería reforzada a partir de la observación de la decoración especialmente en los motivos antropomorfos y felínicos, por lo cual plantean que "...dan la impresión de haber sido trazados de acuerdo con un patrón casi idéntico en piezas diferentes" (Pérez Gollán y Heredia 1987).

Comparando los resultados de nuestro análisis con lo referido por dichos autores respecto de la uni- formidad en los diseños de Ambato, podemos señalar que el caso del valle de Hualfín parecería ser algo diferente. Si bien encontramos patrones semejantes en el diseño y la manufactura tanto de piezas como de motivos, esto se verifica sobre todo en cuanto al tratamiento de la figura felínica. En cambio, en el conjunto de frisos antropomorfos se puede concluir que existe una gran diversidad en la forma de dibujar a la figura humana donde cada imagen parecería representar a un individuo en particular.

Si bien coincidimos con los autores en que la mayoría de las piezas pudieron haber sido elaboradas por artesanos especializados en alfarería ritual, existe un pequeño porcentaje de piezas que no reflejan una gran calidad técnica y artística. En ellas la torpeza en el trazado se manifiesta como propia de una mano aún inexperta o infantil. Esta peculiaridad también puede ser referida a la manufactura de la pieza en términos de grosor de las paredes, simetría de los recipientes y acabado de la superficie.

A partir de las peculiaridades y de la escasez en número de las piezas con frisos antropomorfos, pensamos en primera instancia que las mismas deberían presentarse en tumbas que exhibieran características distintivas respecto del universo relevado.

El análisis contextual revela que, en líneas generales, si bien la muestra sigue los patrones del universo, se acentúa la presencia de indicadores que denotan la importancia relativa de las tumbas estudiadas. Tal el caso de la generalización en el uso de estructuras constructivas y el aumento en la cantidad de objetos cerámicos en los ajuares. A dichos indicadores se les suma la existencia de las vasijas analizadas, que podrían incrementar la significación diferencial en dichas tumbas.

El estudio reseñado intenta constituir un aporte para la identificación de distintas modalidades de representación para las figuras humanas en la entidad sociocultural Aguada, que si bien registra un grado de uniformidad que permite reconocerla como tal, también parece adquirir características regionales. 


\section{REFERENCIAS CITADAS}

ANGELELLI, V., 1950. Recursos minerales de la República Argentina. I. Yacimientos metalíferos. Coni, Buenos Aires.

-1983. Recursos minerales de la República Argentina. I. Yacimientos metalíferos. Coni, Buenos Aires.

ANGELELLI, V. et. al., 1970. Descripción del Mapa Metalogenético de la República Argentina. Minerales Metalíferos. Secretaría de Estado de Minería, Buenos Aires.

BALESTA, B., 1995. El rol temático en las imágenes de La Aguada. Shincal 5: 35-42.

BALFET, H; M. FAUVET-BERTHELOT y S. MONZON, 1992. Normas para la descripción de vasijas cerámicas. Centre D'Etudes Mexicaines et Centramericaines (CEMCA), México D. F.

BERENGUER, J., 1993. Gorros, identidad e interacción en el desierto chileno antes y después del colapso de Tiwanaku. En Identidad y prestigio en los Andes. Gorros, turbantes y diademas. Museo Chileno de Arte Precolombino, pp. 41-64. Santiago.

DONNAN, C. B., 1976. Moche art and iconography. Latin American Center Publication. University of California, Los Angeles.

GONZALEZ, A. R., 1977. Arte precolombino en la Argentina. Filmediciones Valero, Buenos Aires.

GONZALEZ, A. R. y M. BALDINI, 1991. Función y significado de un ceramio de la Cultura La Aguada: Ensayo de interpretación. Boletín del Museo Chileno de Arte Precolombino 5: 23-52.

-1992. La Aguada y el proceso cultural del N.O.A. Origen y relaciones con el Area Andina. Boletín del Museo Regional de Atacama 4: 6-24.
GORDILLO, I., 1990. Entre pirámides y jaguares. Ciencia Hoy 2 (8): 5-9.

LEHMANN NITSCHE, N., 1910 Ms. Catálogo de la Sección Antropológica del Museo de la Universidad Nacional de La Plata. La Plata.

PEREZ GOLLAN, J. A., 1986. Iconografía religiosa andina en el Noroeste Argentino. Boletín del Instituto Francés de Estudios Andinos. Tomo XV, 3/4: 61-72.

PEREZ GOLLAN, J. A. y O. HEREDIA, 1987. Hacia un replanteo de la cultura de La Aguada. Cuadernos Instituto Nacional de Antropología 12: 161/178.

PONCE SANGINES, C., 1969. Tunupa y Ekeko. Estudios arqueológicos de las efigies precolombinas de dorso adunco. Academia Nacional de Ciencias de Bolivia 2, La Paz.

QUILTER, J., 1997. The narrative approach to Moche iconography. Latin American Antiquity 8 (2): 113-134.

SEMPE, C., 1995. Contacto cultural Ciénaga-Aguada en el Depto. Belén, Catamarca. Hombre y Desierto 9: 171-174.

SEMPE, C., S. SALCEDA y M. MENDEZ, 1995. Entierro intrusivo en Barrealito de Azampay. Shincal 5: 43/56.

UBELAKER, D., 1978. Human skeletal remains. Aldine Publishing Company, Chicago.

WEISSER, W. y F. WOLTERS, s/f Ms. Correspondencia y libretas de campo Expediciones Muñiz Barreto. Departamento Arqueología, Museo de La Plata. 